Esta sección esta abierta para todos los lectores de la Revista, a la que pueden enviar sus preguntas, comentarios o críticas a los artículos que hayan sido publicados en los últimos números, teniendo en cuenta la posibilidad de que los autores aludidos puedan responder. Podrá aceptarse la comunicación de investigaciones preliminares, o de intervenciones en brotes que no hayan sido publicados ni sometidos a publicación en otra revista; así como, algunos comentarios sobre problemas de salud pública, ética y educación médica. La extensión máxima aceptable es de 1000 palabras, con un máximo de seis referencias bibliográficas (incluyendo la referencia del artículo que la motivó, cuando sea el caso) y una tabla o figura. Esta puede ser enviada a revmedex@ins.gob.pe.

\section{SOBRE LA TUBERCULOSIS}

\section{[ABOUT TUBERCULOSIS]}

\author{
José Neyra Ramírez ${ }^{1}$
}

Sr. Editor. He leído con gran interés el artículo del doctor Eduardo Ticona titulado: "Tuberculosis ¿se agotó el enfoque biomédico?" (1). Excelente artículo donde el autor orienta su mira a remarcar el aspecto social de la lucha contra esta enfermedad milenaria que no quiere dejar de ser nuestro huésped. Aprovecho estas líneas para agregar algunos comentarios deseando contribuir al artículo en mención.

Infelizmente esta contribución comienza con recordar al autor que en la relación de medidas, casi primitivas que se tenían en épocas anteriores para luchar contra la tuberculosis, no figura la emigración casi multitudinaria, que a través de los siglos se ha conocido, como fue la visita continua de tuberculosos a Jauja. Enfermos que buscaban como esperanza que su emigración a esta bella ciudad produzca la reposición de su salud, después de gozar de la bondad del clima de esta localidad.

Y más aun, desde 1922 en que se inaugura el Sanatorio Olavegoya, la afluencia de pacientes fue mayor cuando era director del sanatorio el doctor José Elías García Frías que sostenía la buena influencia del clima en la cura de la enfermedad y, comentaba: Jauja no cura la tuberculosis pero si la permanencia en esa ciudad de tan magnífico clima levanta las defensas del enfermo, refuerza su poder inmunitario de manera que el paciente, se podría decir, mejora gracias a él mismo.

Así, la guerra a la pobreza la desnutrición y los demás agregados que menciona el doctor Ticona (1), forman parte de la presencia de la tuberculosis.

1 Doctor en Medicina, Profesor Emérito, Facultad de Medicina, Universidad Nacional Mayor de San Marcos. Lima, Perú.

Recibido: 02-02-10 Aprobado: 10-02-10
Desgraciadamente, cuando formulamos estos criterios preventivos y curativos que nos llevarían a profundos cambios sociales encontramos una resistencia muda en las altas esferas económicas, por lo cual, según asevera Ticona, nuestra lucha antituberculosa quedará siempre "cojeando", y es así como compartimos completamente lo expresado en este artículo, que menciona el cambio de la situación social, pero viene el comentario; él señala todo aquello en condicional, "pareciera", "debiera", sería necesario. Yo, en su lugar hubiera hecho afirmaciones en indicativos, a fin que se haga realidad una verdadera lucha antituberculosa.

Permítaseme, terminar este comentario con una palabra del doctor Jave que ha escrito un artículo en el mismo número de la revista ${ }^{(2)}$, que comentamos y en el cual el sugiere la aplicación de una "vacuna" y es por eso que me pregunto: ¿no es suficiente la vacuna antituberculosa BCG?, que la conocemos hace más de 50 años y que bien aplicada es un arma eficaz para la prevención de la primo-infección de la tuberculosis?.

Y sigue mi pregunta ¿es que estoy desfasado? Y tal vez ya no existe la vacuna BCG, tal vez por el hecho de ser jubilado, las armas de otra época ya no son útiles.

\section{Conflictos de Interés}

El autor declara no tener conflictos de interés en la publicación de esta carta.

\section{REFERENCIAS BIBLIOGRÁFICAS}

1. Ticona E. Tuberculosis: ¿se agotó el enfoque biomédico? Rev Peru Med Exp Salud Publica. 2009; 26(3): 273-75.

2. Jave O. Investigando en tuberculosis. ¿Dónde estamos, quiénes somos, hacia dónde nos dirigimos? Rev Peru Med Exp Salud Publica. 2009; 26(3): 276-77.

Correspondencia: José Neyra Ramírez Dirección: Cuenca 126, Surco, Lima, Perú. Correo electrónico: josenera@hotmail.com 